\author{
J. Górka ${ }^{1 *}$, M. Przybyla ${ }^{1}$, M. Szmul ${ }^{2}$, A. Chudzio ${ }^{2}$, D. Ladak $^{2}$ \\ ${ }^{1}$ Silesian University of Technology, Faculty of Mechanical Engineering, Department of \\ Welding Engineering Konarskiego 18a St., 44-100 Gliwice, Poland \\ ${ }^{2}$ FAMET S.A., ul. Szkolna 15a, 47-225 Kędzierzyn-Koźle, Poland \\ *jacek.gorka@polsl.pl
}

\title{
ORBITAL TIG WELDING OF TITANIUM TUBES WITH PERFORATED BOTTOM MADE OF TITANIUM-CLAD STEEL
}

\begin{abstract}
The article presents problems accompanying the industrial TIG welding (142) of a heat exchanger perforated bottom made of steel clad with titanium B265 grade 1 with tubes made of titanium B338 grade 2. Researchrelated tests involved the making of test plates containing simulated imperfections formed during orbital welding. The above-named imperfections resulted from insufficient gas shielding during the welding process, the improper positioning of the tungsten electrode (excessively large or overly small circumference, around which the orbital welding process was performed), an excessive electrode travel rate being the consequence of an improperly set welding programme as well as excessively high welding current. Initial tests enabled the development of the orbital TIG welding of titanium tubes with the perforated bottom made of titanium-clad steel, satisfying acceptance criteria applied during commissioning.
\end{abstract}

Keywords: orbital welding; TIG, perforated bottom; titanium; clad steel

\section{INTRODUCTION}

Presently, industry is facing numerous welding-related challenges connected with an increasingly large range of available materials as well as with requirements concerned with joining processes performed using well-known welding methods [1-5]. The present stage of technological development enables the design of welded structures involving the use of various materials including steels, aluminium alloys, nickel alloys, magnesium alloys or titanium alloys. Each of the above-presented materials requires a different approach when designing a related joining technology (due to varying physical properties of the aforesaid materials). Because of their high relative strength and very high corrosion resistance, titanium alloys are a perfect choice when designing structures exposed to considerable loads or operated in aggressive corrosion environments. Titanium is used primarily in the power engineering industry, chemical industry, food industry as well as in the aviation industry. One of the key aspects in terms of power engineering is to ensure the proper and continuous operation of equipment for a long time (up to 30 or even 40 years). The foregoing explains the 
popularity of titanium used in heat exchangers, where the cooling medium is water rich in chlorides and sulphides [6-11]. The aforesaid water combined with high temperature creates a corrosive environment affecting heat exchanger elements. Presently, shell-and-tube heat exchangers constitute half of heat exchanger types used in industrial systems. The medium responsible for the discharge of heat imposes certain restrictions in terms of materials which can be used to make tubes located inside the heat exchanger [11-17]. Highly corrosive seawater or water rich in sulphides and chlorides flowing through heat exchanger tubes necessitates the use of titanium alloys. In each of shell-and-tube heat exchanger types, tubes have to be connected with a perforated plate (tubes are fixed freely, i.e. they are not connected with bulkheads). Technologies applied for the joining of tubes with perforated walls include welding, tube expanding, adhesive bonding or explosion welding [18-22].

\section{EXPERIMENTAL}

The study presented in the article aimed to analyse problems accompanying the orbital TIG welding (142) of a perforated bottom (of a heat exchanger) made of steel clad with titanium B265 grade 1 with tubes made of titanium B338 grade 2. The research-related tests involved the making of a test plate containing simulated welding imperfections typical of the aforesaid types of joints.

\section{Test joint with simulated welding imperfections}

The plate used in the tests was made of unalloyed steel A516M grade 485 (P256GH) explosion-clad with titanium B265 grade 1. The test plate, having dimensions of $300 \mathrm{~mm} \mathrm{x}$ $300 \mathrm{~mm}$, contained a $60 \mathrm{~mm}$ thick unalloyed steel layer and $5 \mathrm{~mm}$ thick titanium plated coating (see Fig. 1). The plate also contained 20 drilled holes (arranged in triangles), into which tubes having a diameter of $34.93 \mathrm{~mm}$ and made of $0.7 \mathrm{~mm}$ thick titanium B338 grade 2 were welded. The chemical composition of the test materials is presented in Table 1.

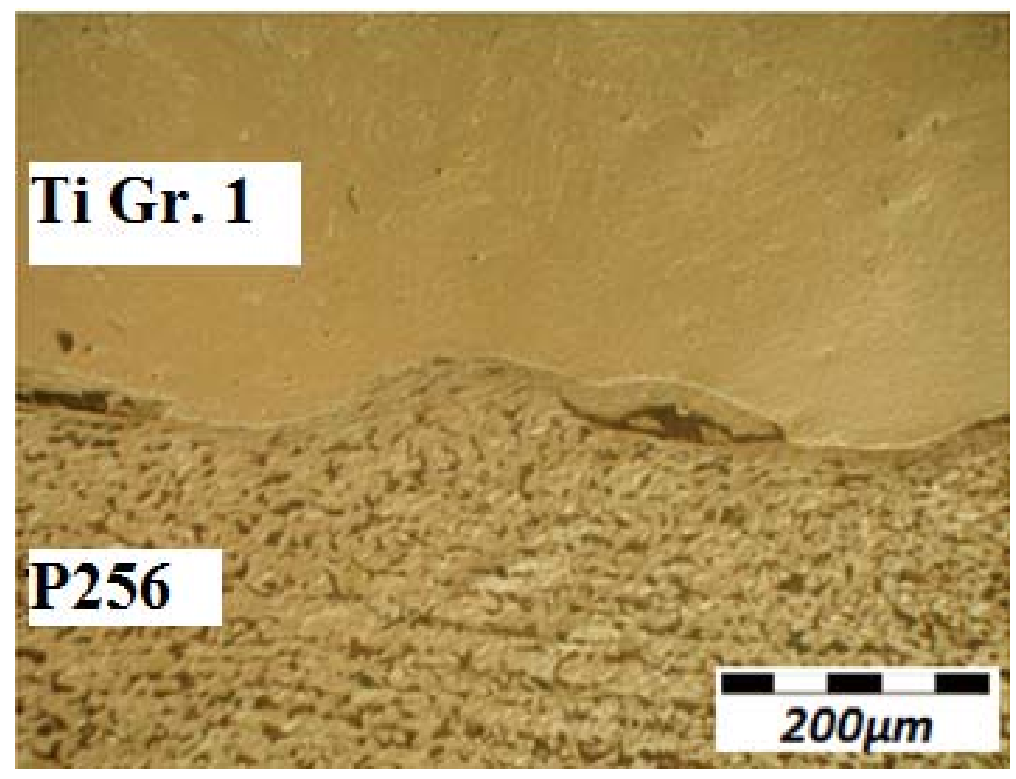

Fig. 1. Titanium-clad plate

Table 1. Chemical composition of the tested materials 


\begin{tabular}{|c|c|c|c|c|c|c|c|c|c|c|c|}
\hline & \multicolumn{10}{|c|}{ Chemical composition, [wt. \%] } & \\
\cline { 2 - 12 } & $\mathrm{C}$ & $\mathrm{Si}$ & $\mathrm{Mn}$ & $\mathrm{Al}$ & $\mathrm{Cr}$ & $\mathrm{S}$ & $\mathrm{Fe}$ & $\mathrm{H}$ & $\mathrm{N}$ & $\mathrm{O}$ & $\mathrm{Ti}$ \\
\hline $\begin{array}{c}\text { A516M } \\
\text { Gr. 485 }\end{array}$ & $0.1-0.2$ & 0.6 & 1.05 & 0.02 & 0.3 & 0.03 & Rest & - & - & - & \\
\hline $\begin{array}{c}\text { Titanium } \\
\text { Grade 1 }\end{array}$ & $\leq 0.1$ & & & & & & $\leq 0.2$ & $\leq 0.015$ & $\leq 0.03$ & $\leq 0.18$ & Rest \\
\hline $\begin{array}{c}\text { Titanium } \\
\text { Grade 2 }\end{array}$ & $\leq 0.1$ & & & & & & $\leq 0.3$ & $\leq 0.015$ & $\leq 0.03$ & $\leq 0.25$ & Rest \\
\hline
\end{tabular}

The welding process was performed using an orbital TIG welding machine. The simulated welding imperfections reflected insufficient gas shielding during the process, the improper positioning of the tungsten electrode (excessively large or overly small circumference, around which the orbital welding process was performed), an excessive electrode travel rate resulting from an improperly set welding programme as well as excessively high welding current. The test place joint is presented in Figure 2a.

\section{Test joints}

The analysis of the plate with simulated imperfections was followed by the making of a test plate subjected to visual, penetrant, radiographic and metallographic tests. The welding current (i.e. reversed polarity DC) amounted to 55A, the welding speed was $20 \mathrm{~cm} / \mathrm{min}$, arc voltage was restricted within the range of $7.0 \mathrm{~V}$ to $9.0 \mathrm{~V}$, the heat input amounted to 0.54 $\mathrm{kJ} / \mathrm{cm}$ and the shielding gas outflow rate $\left(99.998 \%\right.$ pure argon) amounted to $30 \mathrm{dm}^{3} / \mathrm{min}$. In addition, the diameter of the tungsten electrode used in the process amounted to $1.6 \mathrm{~mm}$, whereas its tip was sharpened at an angle of $30^{\circ}$. The test plate joint is presented in Fig. $2 \mathrm{~b}$.

a)

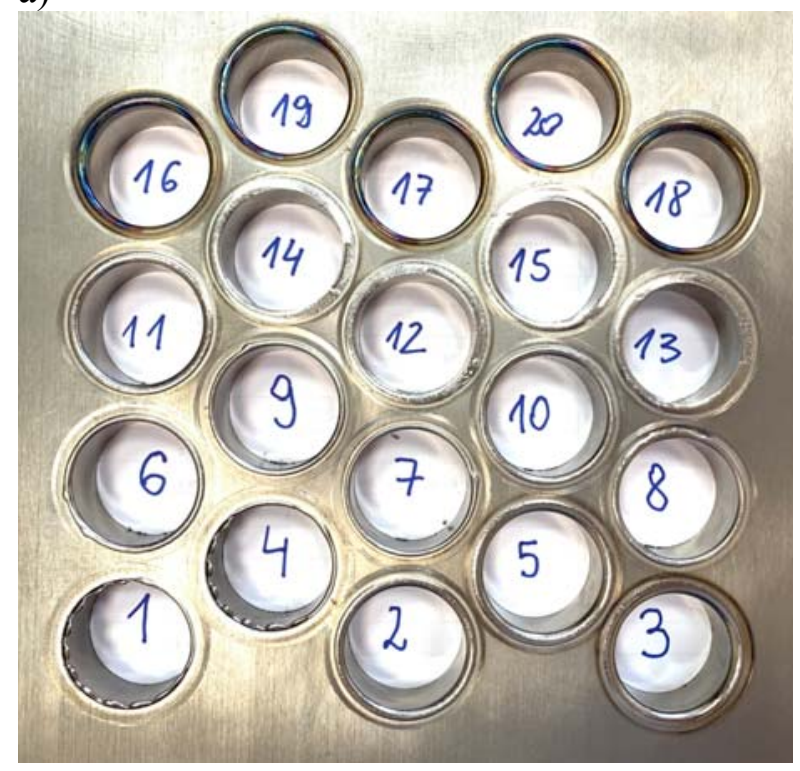

b)

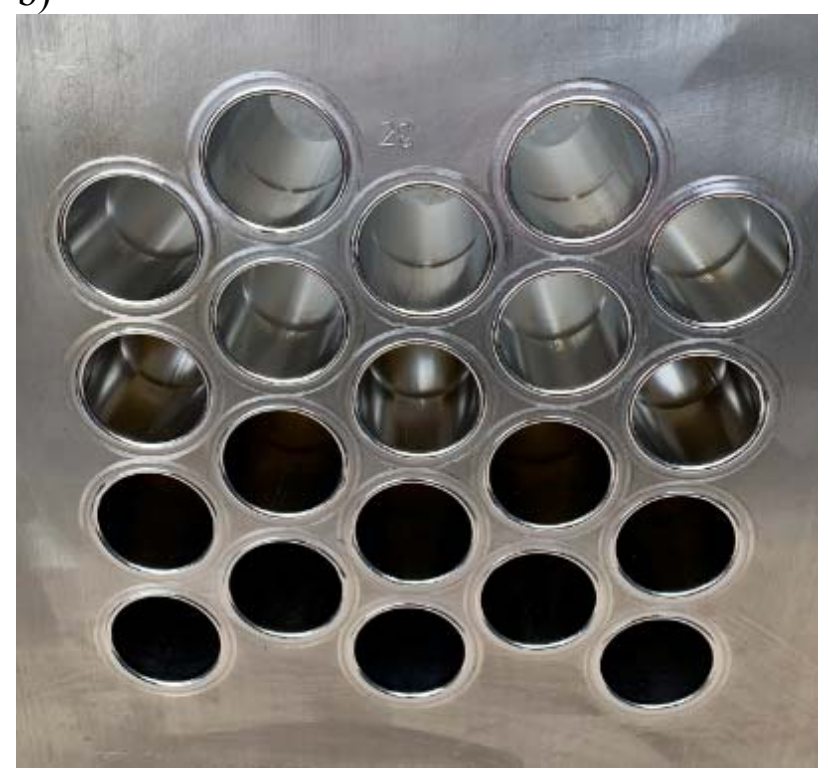

Fig. 2. Test plate: a) with simulated imperfections, b) made in accordance with the technology 
The test plate containing simulated imperfections was subjected to visual tests. The visual assessment results are presented in Table 2 and Figure 3.

Table 2. Reasons responsible for the formation of welding imperfections

\begin{tabular}{|c|c|}
\hline Joint no. & Parameters/imperfections/description \\
\hline 1,4 & $\begin{array}{l}\text { Joints no. } 1 \text { and } 4 \text { were made in accordance with a previously adopted } \\
\text { technology, yet the trajectory of the electrode was intentionally reduced in } \\
\text { comparison with the diameter of the area, where the joint was to be made. } \\
\text { Figure 3a presents a "ragged-like frill" formed because of a failure to partially } \\
\text { melt the plated coating (only the tube was melted). }\end{array}$ \\
\hline $2,3,5$ & $\begin{array}{l}\text { Joints no. } 2,3 \text { and } 5 \text { were made in accordance with a previously adopted } \\
\text { technology, yet, the parameter of welding current in the welding programme } \\
\text { was increased (intentionally). In terms of joint no. } 2 \text {, the welding current } \\
\text { amounted to } 80 \mathrm{~A} \text {, as regards joint no. 5; the welding current amounted to } \\
100 \mathrm{~A} \text {, whereas in terms of joint no. 3, the welding current amounted to } 120 \mathrm{~A} \text {. } \\
\text { In accordance with a related Welding Procedure Specification (WPS), the } \\
\text { welding current should have amounted to 55A. The shape and the appearance } \\
\text { of the weld face indicated that the increase in the welding current resulted in } \\
\text { the obtainment of excessively high temperature responsible for the formation } \\
\text { of an overheated area (indicated by the darker-coloured areola-like shape } \\
\text { metallographic observations), disqualifying the weld during the process of } \\
\text { acceptance (Fig 3b). }\end{array}$ \\
\hline $6,7,9$ & $\begin{array}{l}\text { Joints no. } 6,7 \text { and } 9 \text { were made in accordance with a previously adopted } \\
\text { technology, yet the parameter of an electrode travel rate in the welding } \\
\text { programme was modified. In each subsequent joint, the above-named } \\
\text { parameter was increased in order to obtain the visibly narrow weld face and, } \\
\text { consequently, the unacceptable geometry of the joint (see Fig. 3c). }\end{array}$ \\
\hline 8,10 & $\begin{array}{l}\text { Joints no. } 8 \text { and } 10 \text { were made in accordance with a previously adopted } \\
\text { technology, yet, before the welding process, petrolatum was applied on the } \\
\text { area designated for joint no. } 10 \text {, whereas graphite-based lubricant was applied } \\
\text { on the area designated for joint no. } 8 \text { (see Fig } 3 \mathrm{~d} \text { ). }\end{array}$ \\
\hline $\begin{array}{c}11,12,13 \\
14,15\end{array}$ & $\begin{array}{l}\text { Joints no. } 11,12,13,14 \text { and } 15 \text { were made in accordance with a previously } \\
\text { adopted technology, yet the trajectory of the electrode was intentionally preset } \\
\text { as slightly exceeding the diameter of the area, where the joint was to be made. } \\
\text { Joints nos. } 12,13,14 \text { and } 15 \text { clearly revealed that a fragment of the tube was } \\
\text { not melted (see Fig. } 3 \mathrm{e} \text { ). }\end{array}$ \\
\hline $\begin{array}{c}16,17,18 \\
19,20\end{array}$ & $\begin{array}{l}\text { Joints no. } 16,17,18,19 \text { and } 20 \text { were made in accordance with a previously } \\
\text { adopted technology, yet surrounding air was intentionally allowed to access } \\
\text { the weld area in order to obtain blue-coloured discolouration (each weld } \\
\text { started at the } 9 \text { th hour) resulting from the oxidation of the weld. In turn, the } \\
\text { straw-like/golden colour resulted from the oxygenation of the already heated } \\
\text { area (by electric arc), yet the discharge of heat proceeded otherwise (see Fig. } \\
\text { 3f). }\end{array}$ \\
\hline
\end{tabular}



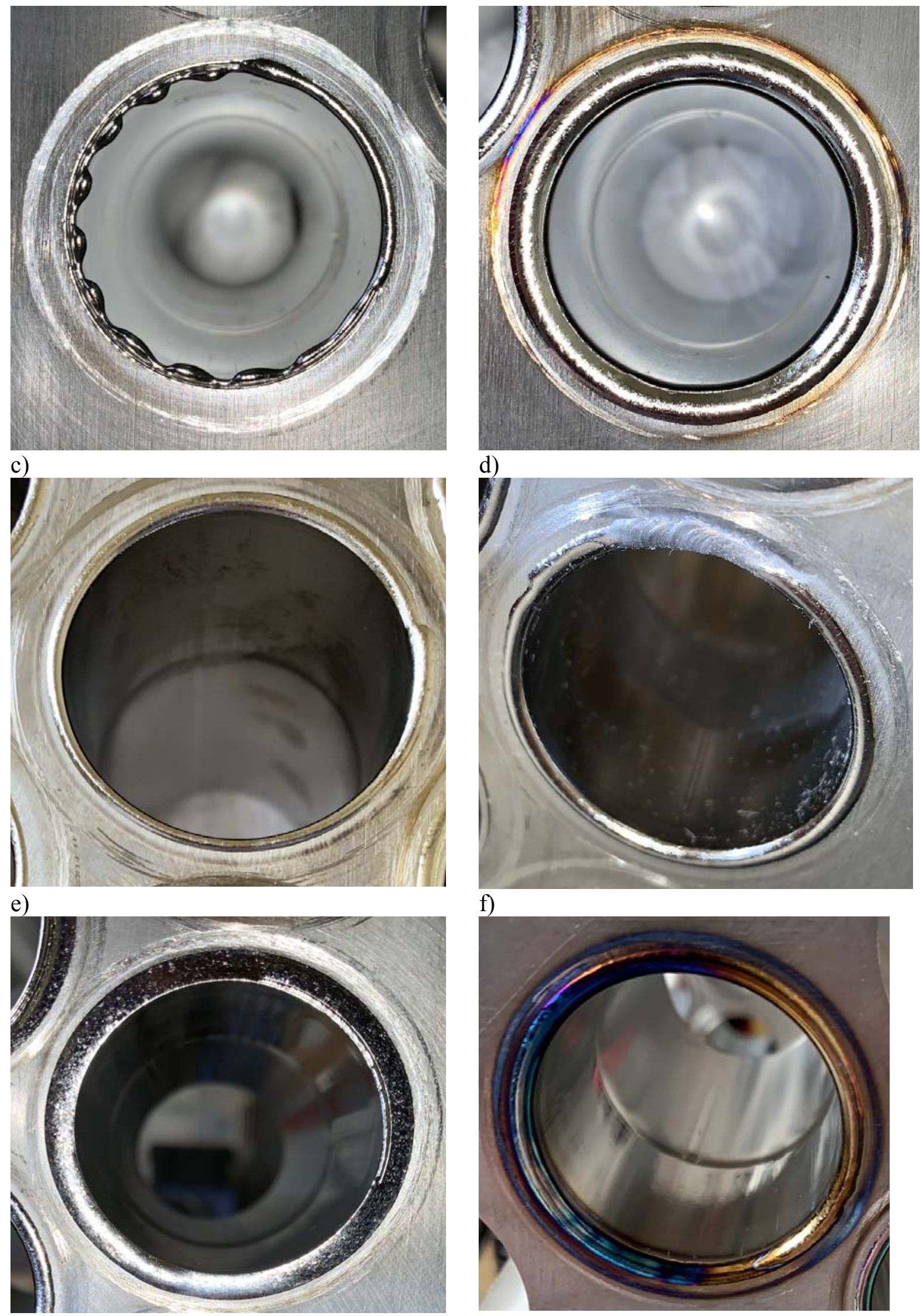

Fig. 3. Joints containing welding imperfections 
The test joint made in accordance with a previously adopted technology was subjected to visual tests (VT) in accordance with the PN-EN ISO 17637:2011 standard; the adopted acceptance criteria were based on the PN-EN ISO 15614-8:2005 standard. The visual tests did not reveal the presence of imperfections exceeding the previously adopted acceptance criteria. The penetrant tests performed in accordance with the PN-EN ISO 3452-1:2013 standard (acceptance criteria based on PN-EN ISO 23277:2010) did not reveal the presence of welding imperfections (see Figure 4).

a)

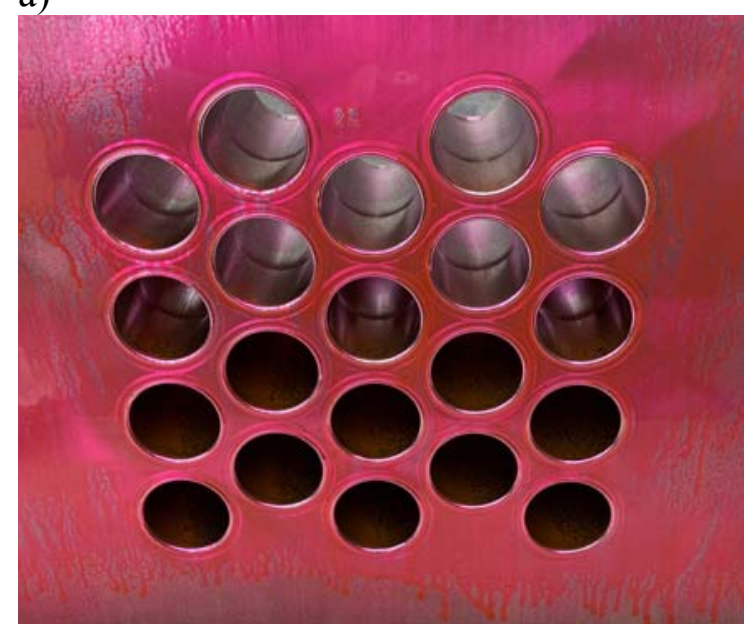

b)

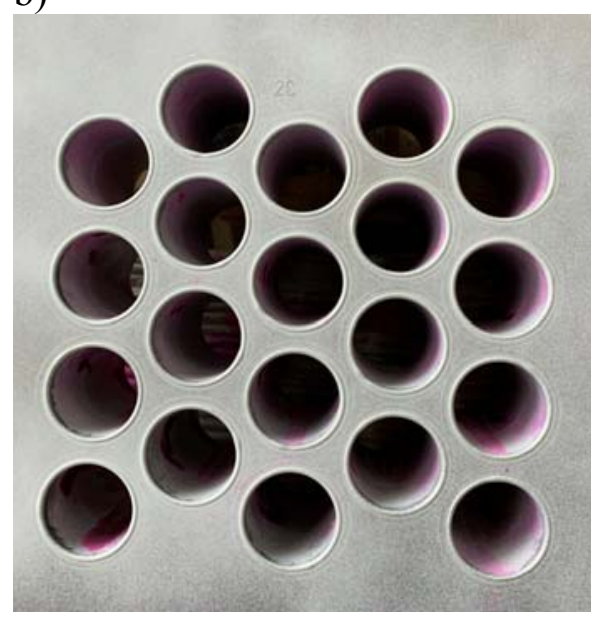

Fig. 4. Test plates subjected to penetrant tests; a) plate containing simulated imperfections and b) plate made in accordance with the technology

The radiographic tests (RT) were performed in accordance with the PN-EN ISO 176361:2013 standard; the adopted acceptance criteria were based on the PN-EN ISO 6520-1:2009 standard. The interpretation of the RT results did not reveal the presence of imperfections preventing acceptance in accordance with the previously adopted acceptance criteria (see Fig. $5)$.

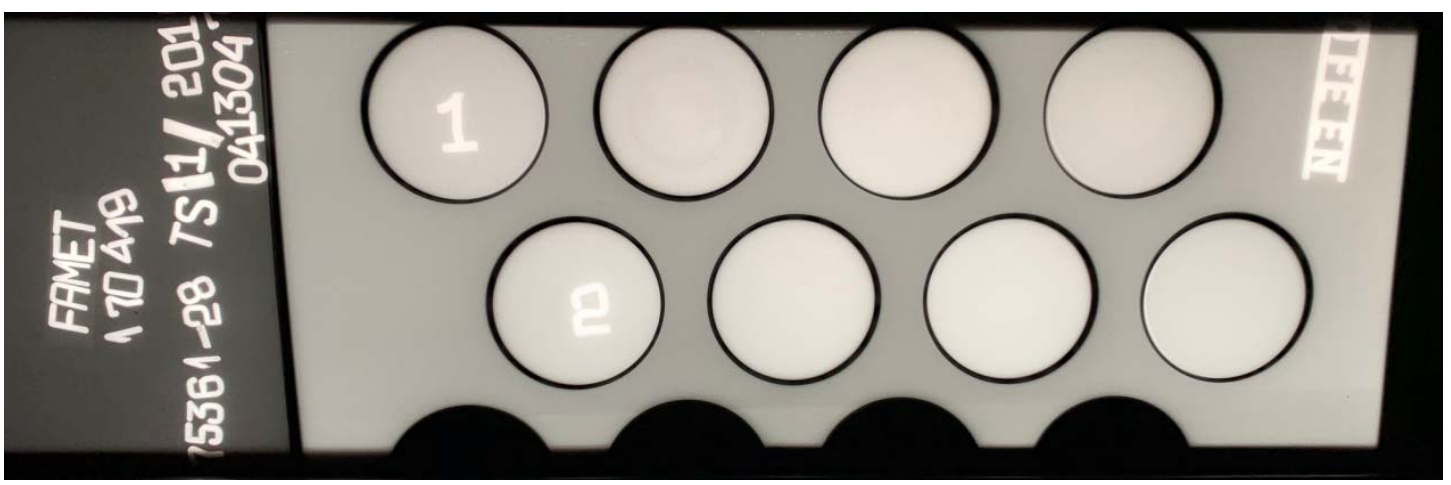

Fig. 5. RT image

In subparagraph 7.2.5 Macroscopic Tests, the PN-EN ISO 15614-8 standard specifies weld dimension a. The aforesaid dimension should be equal to the radius of the largest circle entirely inscribed into the weld, the centre of which is located at the lowest point of the weld root. The size of the dimension must satisfy a related criterion, where $a \geq 0.9 \mathrm{t}$ and $\mathrm{t}$ is the thickness of the tube wall. The size of parameter a was measured in the metallographic 
observations. The obtained values did not exceed $0.63 \mathrm{~mm}$ (in relation to a tube with wall thickness $\mathrm{t}=0.7$, dimension $0.9 \mathrm{t}$ amounts to $0.63 \mathrm{~mm}$ ). The macroscopic tests revealed that, in terms of geometry, the weld satisfied the requirements of the PN-EN ISO 15614-8:2005 standard (see Fig. 6).

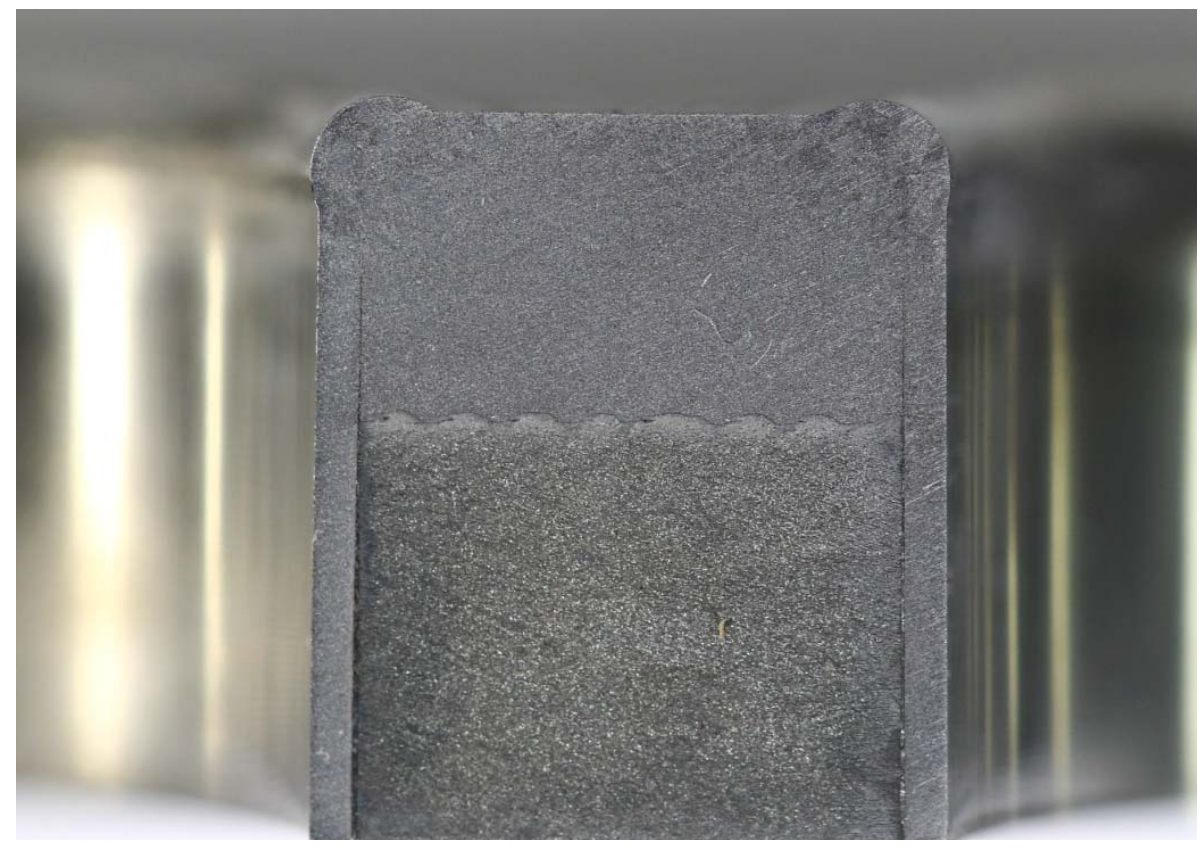

Fig. 6. Macrostructure of the welded joint

Figure 7 presents the microstructure of the unoxygenated weld, composed of large phase $\alpha$ and phase $\alpha^{\prime}$ (titanium martensite) grains, inside which it is possible to observe twins. The grains are so large that one grain is part both of the weld root and of the weld face. The abovepresented phenomenon is connected with the formation of large grains during the crystallisation of the weld metal. The dark horizontal line results from the existence of a gap between the tube and the perforated plate (due to insufficient tube expanding). The joint microstructure does not reveal any imperfections. Figure 8 presents the microstructure of the oxygenated weld magnified 100 times. The specimen was sampled in cross-section containing the blue-coloured discolouration. It is possible to observe the acicular structure in the form of the basket-like tangle of phase $\alpha$. The feather-like precipitates within the phase result from the peritectic transformation occurring between $\mathrm{Ti}$ and TiO. The dark areas between the precipitates of phase $\alpha$ constitute residue after metastable phase $\beta$. The above-presented microstructure indicates the oxygenation of the weld and its significant brittleness. The foregoing demonstrates the correlation between the (colour of) discolouration of the weld face and its properties. 


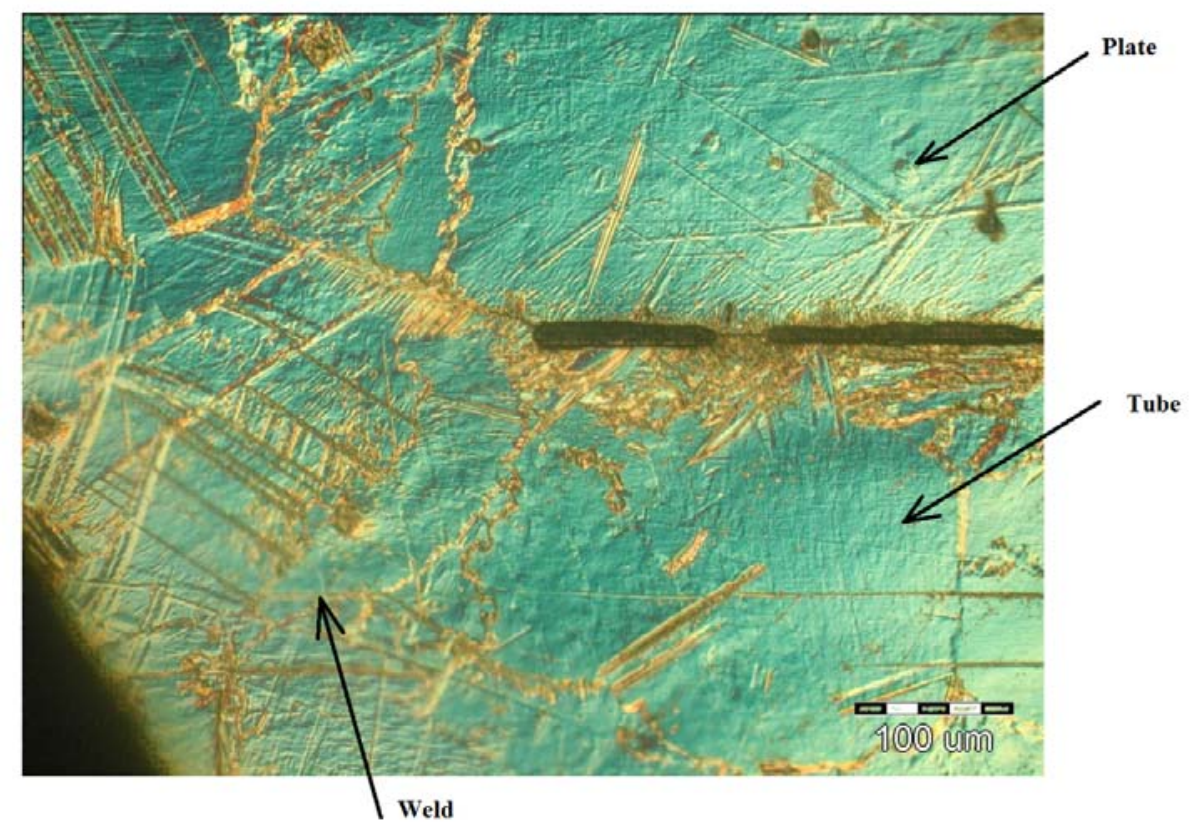

Fig. 7. Microstructure of the properly gas-shielded weld; Nomarski interference contrast

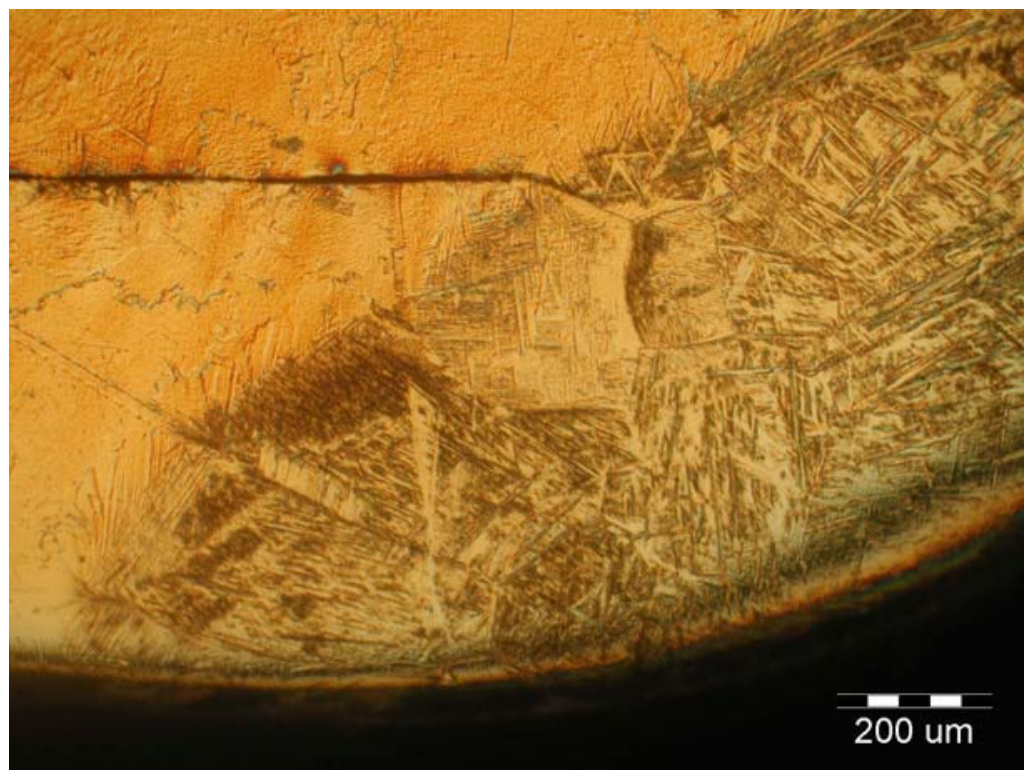

Fig. 8. Microstructure of the oxygenated weld of the oxygenated joint (blue-coloured discolouration); Nomarski interference contrast

\section{SUMMARY}

The tests of the orbital TIG welding (142) of the heat exchanger perforated bottom made of steel clad with titanium B265 grade 1 with the tubes made of titanium B338 grade 2 justified the formulation of the following conclusions:

- obtainment of proper joints made of titanium requires the use of tight and intense inert gas (e.g. argon) shielding;

- pre-weld joint preparation involving the thorough removal of impurities from the future weld area significantly reduces the formation of welding imperfections; 
- because of the fact that the electrode travel rate, the distance between the tungsten electrode and the material being welded as well as welding current are crucial factors affecting the geometry of the joint, the above-named parameters must be subjected to continuous monitoring;

- design of a method 142-based welding technology enabling the welding of titanium tubes with the perforated plate requires the performance of numerous analyses and tests aimed to determine appropriate welding parameters during the implementation of the technology in production conditions,

- test plate made following related technological assumptions satisfied all requirements necessary for welding procedure qualification concerning the welding of tubes with perforated plates;

- non-destructive tests and macrographic tests did not reveal the existence of any problems concerning the satisfaction of related criteria specified in the PN-EN ISO 15614-8:2005 standard;

- the microstructure of the weld of large phase $\alpha$ and phase $\alpha^{\prime}$ (titanium martensite) grains, inside which it is possible to observe twins.

\section{REFERENCES}

1. Vandewynckéle, A, Vaamonde, E, Fontán, M., Herwig, P., Mascioletti, A. (2013). Laser welding head tailored to tube-sheet joint requirements for heat exchangers manufacturing. Physics Procedia, 41, 144-152.

2. Varbai, B., Pickle, T., Májlinger, K. (2019). Effect of heat input and role of nitrogen on the phase evolution of 2205 duplex stainless steel weldment. International Journal of Pressure Vessels and Piping, 176, 103952.

3. Sajek, A. (2019). Application of FEM simulation method in area of the dynamics of cooling AHSS steel with a complex hybrid welding process. Welding in the World, 63(4), 1065-1073.

4. Gietka, T., Ciechacki, K., Kik, T. (2016). Numerical simulation of duplex steel multipass welding. Archives of Metallurgy and Materials, 61, 1975-1983.

5. Górka, J., Klimpel, A. (1995). A technology for the welding of tubes to perforated clad tube plates. Welding International, 9, 776-780.

6. Pańcikiewicz, K., Tuz, L., Zielińska-Lipiec, A. (2014). Zinc contamination cracking in stainless steel after welding. Engineering Failure Analysis, 39, 149-154.

7. Skowrońska, B., Chmielewski, T., Pachla, W., Kulczyk, M., Skiba, J., Presz, W. (2019). Friction Weldability of UFG 316L stainless steel. Archives of Metallurgy and Materials, 64, 1051-1058.

8. Winczek, J., Gawronska, E., Gucwa, M., Sczygiol, N. (2019). Theoretical and experimental investigation of temperature and phase transformation during SAW overlaying. Applied Sciences, 9(7), 1472.

9. Talkington, J., Harwig, D., Castner. H., Mitchell, G. (2000). Development of titanium weld color inspection tools. Welding Journal, 79(3), 35-38.

10. Margolin. H., Nielsen, J.P. (1960). Titanum Metallurgy - Modern materials advances in development and aplications. New York - London: Academic Press 2, 225 - 325. 
11. Shankar, A. R., Sole, R., Thyagarajan, K., George, R. P., Mudali, U. K. (2019). Failure analysis of titanium heater tubes and stainless steel heat exchanger weld joints in nitric acid loop. Engineering Failure Analysis, 99, 248-262.

12. Lathabai, S., Jarvis. B.L., Barton, K.J. (2001). Comparison of keyhole and conventional gas tungsten arc welds in commercially pure titanium. Materials Science and Engineering A, 299, 8193.

13. Farrahi, G. H., Chamani, M., Kiyoumarsioskouei, A., Mahmoudi, A. H. (2019). The effect of plugging of tubes on failure of shell and tube heat exchanger. Engineering Failure Analysis, 104, 545-559.

14. Kumar, K., Masanta, M., Sahoo, S. K. (2019). Microstructure evolution and metallurgical characteristic of bead-on-plate TIG welding of Ti-6Al-4V alloy. Journal of Materials Processing Technology, 265, 34-43.

15. Khorshidi, J., Heidari, S. Design and construction of a spiral heat exchanger. Advances in Chemical Engineering and Science, 6, 1-8.

16. Tomków, J., Fydrych, D., Rogalski G., Łabanowski J. (2019). Effect of the welding environment and storage time of electrodes on the diffusible hydrogen content in deposited metal. Revista de Metalurgia, 55, e140.

17. Prabhat, K., Aravinda, P. (2014). An overview of welding aspects and challenges during manufacture of intermediate heat exchangers for 500MWe prototype fast breeder reactor. Procedia Engineering, 86, 173 - 183.

18. Leonov, V.P., Mikhailov, V.I., Yu, I. (2016). Welding of high-strength titanium alloys of large thicknesses for use in marine environments. Inorganic Materials: Applied Reaserch, 7, 877-883.

19. Lothongkum, G., Chaumbai, P., Bhandhubanyong P. (1990). TIG pulse welding of 304L austenitic stainless steel in flat, vertical and overhead positions. Journal of Materials Processing Technology, 89-90, 410-414.

20. Lisiecki, A. (2016). Effect of heat input during disk laser bead-on-plate welding of thermomechanically rolled steel on penetration characteristics and porosity formation in the weld metal. Archives of Metallurgy and Materials, 61, 93-102.

21. Benway, A. (2000). Advancements in automatic orbital welding expand its use, provide welders with more option. Industrial Maintenance \& Plant Operation, 61, 22.

22. Kosturek, R., Wachowski, M., Śnieżek, L., Gloc, M. (2019). The influence of the post-weld heat treatment on the microstructure of Inconel 625/carbon steel bimetal joint obtained by explosive welding. Metals, 9(2), 246. 